\title{
Unilateral Deforming Warthin's Tumor: Case Report and Literature Review
}

\author{
Ioana Maria Porfire*, Nicoleta Pers, Anda Apostol ${ }^{\circledR}$ and Silviu Albu
}

II-nd Department of Otorhinolaryngology, Iuliu Hatieganu University of Medicine and Pharmacy, Str. Republicii nr. 18, 400015 Cluj-Napoca, Romania; persnicoleta@gmail.com (N.P.); andapstl@yahoo.com (A.A.); silviualbu63@gmail.com (S.A.)

* Correspondence: ioanaporfire@yahoo.com

Received: 28 July 2020; Accepted: 28 August 2020; Published: 10 September 2020

\begin{abstract}
Warthin's tumor (WT) is the second most common benign tumor of the parotid gland. Located almost exclusively in the parotid gland and presenting a slow growth rate, WT usually does not exceed $4 \mathrm{~cm}$ and rarely benefits from early surgical treatment. The aim of this paper is to present a case of giant parotid Warthin's tumor. The occurrence of large and deforming WT is rare, previous research showed a single similar reported case. The patient's computed tomography scans showed a solid and cystic $15 \times 13 \mathrm{~cm}^{2}$ mass of the parotid gland, without visible signs of invading the adjacent structures. Superficial parotidectomy with tumor excision was performed, with preservation of glandular and facial nerve functions. The paper also presents a brief literature review addressing the main controversies regarding etiopathology, epidemiology, diagnostic methods and treatment options for this parotid gland tumor.
\end{abstract}

Keywords: Warthin tumor; parotid gland; superficial parotidectomy

\section{Introduction}

Warthin's tumor is the second most frequent benign parotid gland neoplasia, presenting as an asymptomatic slow-growing tumor [1]. Most commonly, patients seek medical advice, due to aesthetic criteria and neck stiffness [1].

For diagnosis of WT, fine needle aspiration biopsy (FNAB) is recommended by most authors due to the low rate of side effects, cost-effectiveness and its high sensitivity and specificity [2]. Imaging diagnosis can be made using CT scan or MRI, depending on the experience of the radiologist [3]. Superficial parotidectomy or even extracapsular dissection are preferred over total parotidectomy for excision of this type of tumor, due to the lower rates of facial nerve damage and glandular dysfunction [4].

We report the case of a patient with a massive, deforming Warthin's tumor of the left parotid gland and provide a literature review on the management of this pathology.

\section{Case Presentation}

Informed consent was obtained from the patient for publication of this case report and accompanying images. The study was conducted in accordance with the Declaration of Helsinki, and the protocol was approved by the Ethics Committee of Iuliu Hatieganu University of Medicine and Pharmacy (No. 288/09.09.2020).

A 71-year-old male, presented with a left parotid mass, slowly evolving over a period of 12 years, causing considerable disfigurement. Except for the neck stiffness caused by the size and weight of the tumor, the patient was asymptomatic. The patient presented grade I obesity, occasionally consumed alcohol and his medical history was not significant. 
Physical examination revealed a massive swelling of the left parotid region, measuring $15 \times 13 \mathrm{~cm}^{2}$ (Figure 1), extending from the left preauricular region to the supraclavicular fossa. The mass was firm on palpation with fluctuation in certain areas, reduced mobility and the overlying skin was stretched, presenting telangiectasias. There were no signs of facial nerve paralysis and no regional lymph nodes. The intraoral examination revealed normal mucosa and Stensen's opening, with normal salivation during gland stimulation.

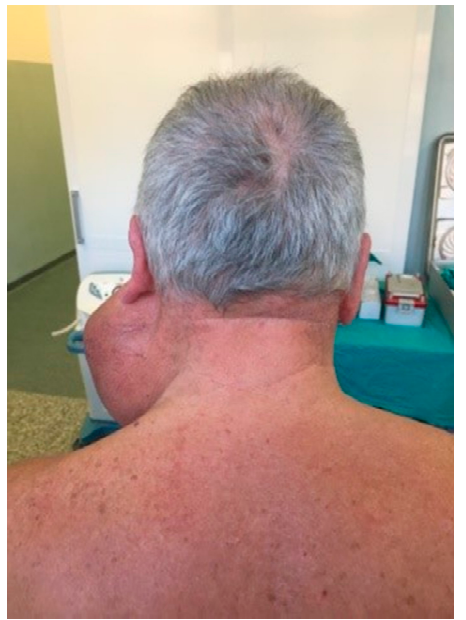

(a)

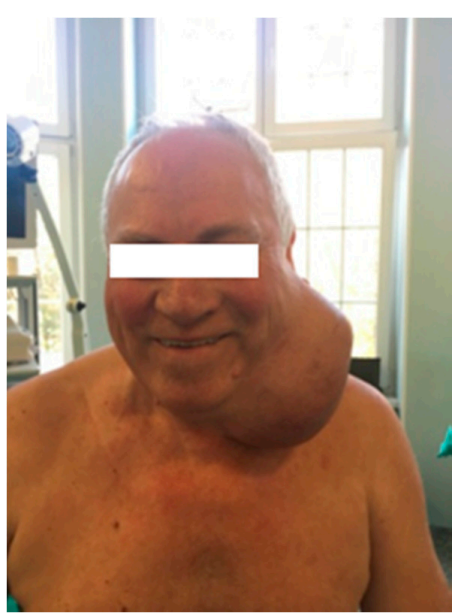

(b)

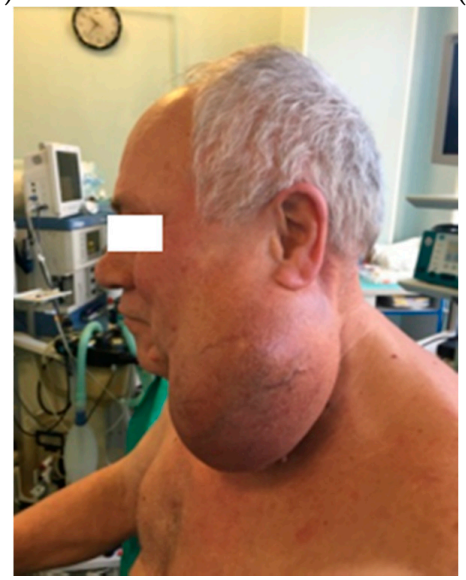

(c)

Figure 1. Patient with left parotid tumor: (a) posterior incidence; (b) anterior incidence; (c) left lateral incidence.

Contrast enhanced computed tomography (Figure 2) revealed a heterogeneous solid cystic lesion measuring $96 \mathrm{~mm} / 102 \mathrm{~mm} / 136 \mathrm{~mm}$, with moderate enhancement within the superficial lobe of the left parotid gland and extension toward the left supraclavicular fossa. The tumor was well defined, with no muscular infiltration or calcifications and the cystic component was displayed as intralesional lower attenuation. The most likely imaging diagnosis was of benign left parotid gland tumor, most probably Warthin's tumor.

A superficial parotidectomy was performed via modified Blair's incision with anterior extension of approximately $15 \mathrm{~cm}$ (Figure 3). Tumor dissection was carried with elevation of the anterior and posterior flaps, down to the posterior belly of the digastric muscle, with difficult facial nerve identification due to the tumor size and modified anatomy. Dissection was continued anteriorly and superiorly, isolating all facial nerve's branches, without causing vascular and nervous injury. Subsequently, the excess skin was excised and an intradermic suture was performed. 


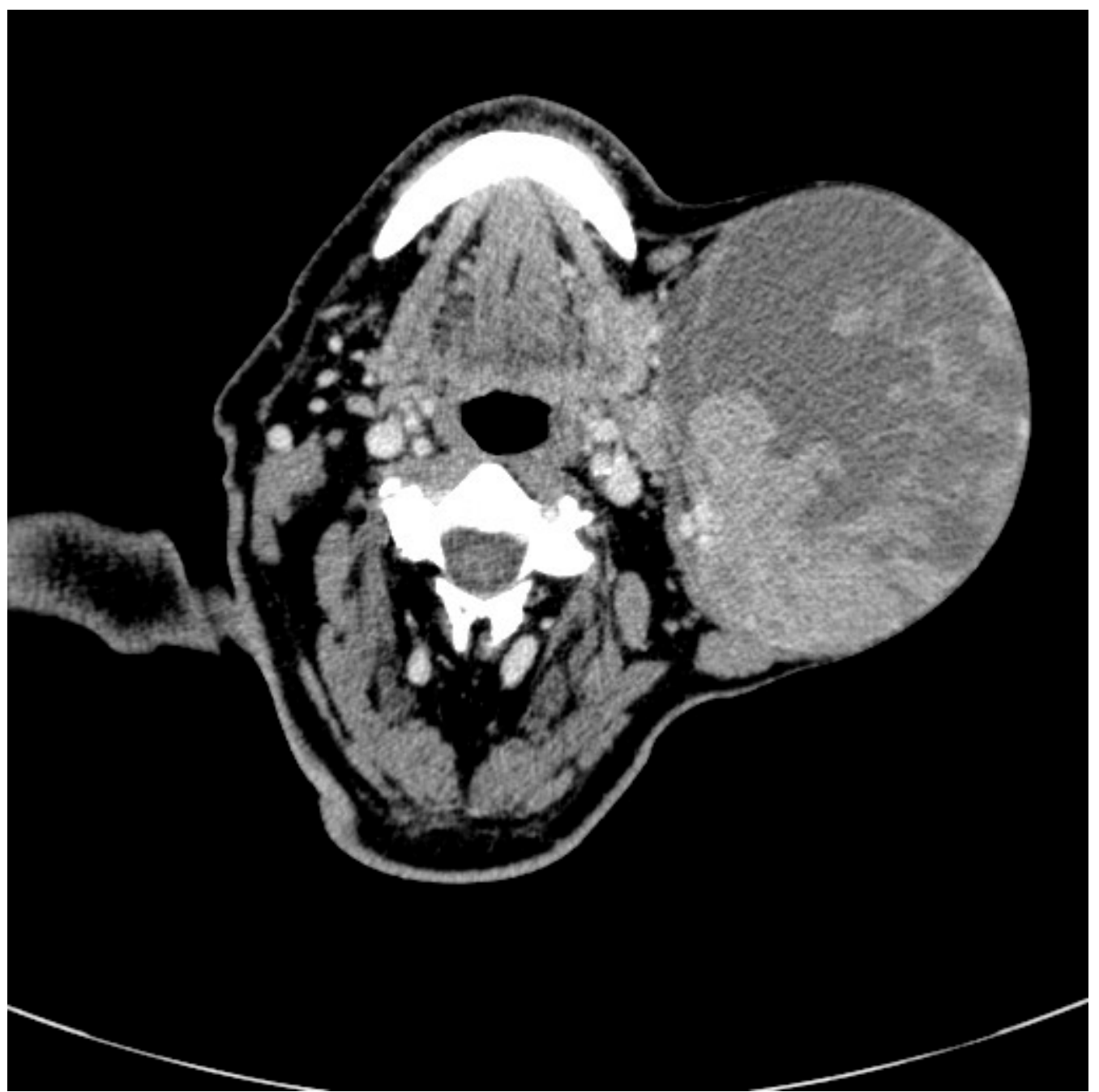

Figure 2. Radiographic features of Warthin tumor: Axial non-enhanced computed tomography images in bone window show a nodular lesion (see arrow) in the left parotid gland involving the superficial lobe, with dimensions of $15 \mathrm{~cm} / 13 \mathrm{~cm}$.
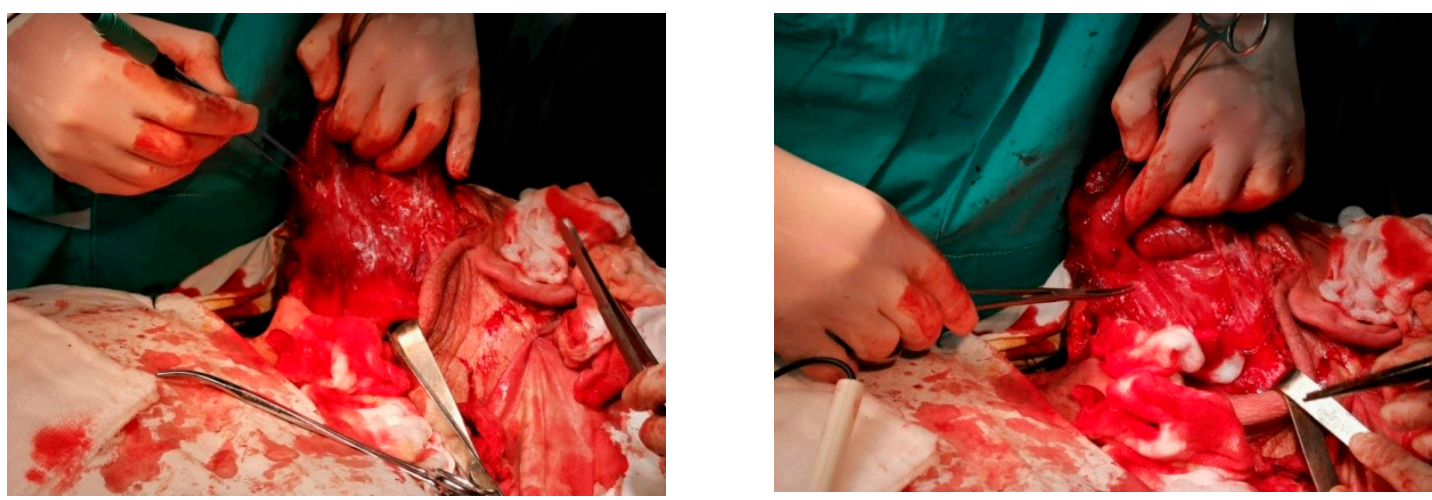

Figure 3. Intraoperative picture revealing the tumor located in the superficial lobe of the left parotid gland during tumor isolation and subsequent tumor removal.

The resection piece measured 10/8, 5/5 cm after drainage of approximately $50 \mathrm{~mL}$ of grayish slimy liquid (Figure 4).

The histopathological examination described epithelial and lymphoid tissue, separated by a basal membrane; pseudostratified epithelial cells containing small eosinophilic particles within the 
cytoplasm and lymphoid cell aggregates (lymphoid follicles). Inside the cysts, large areas of pink dye in an unorganized substance, degenerative epithelial cells and some inflammatory cells were described (Figure 5).

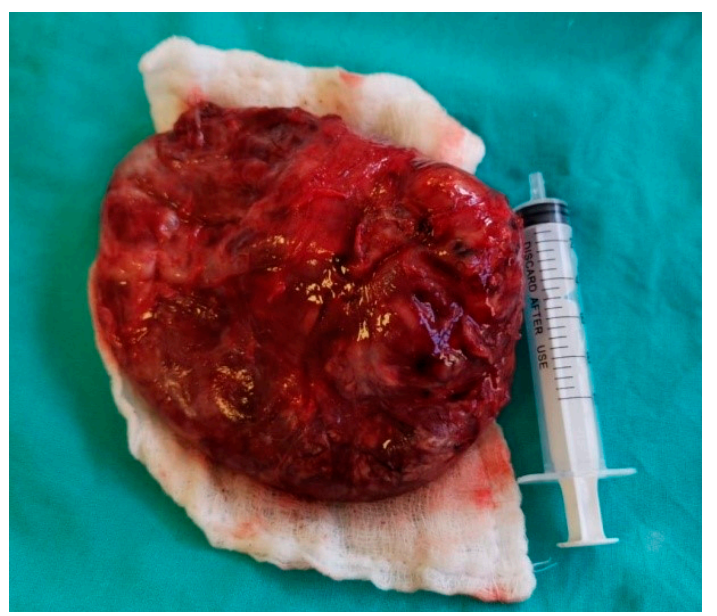

Figure 4. Tumor resection piece measuring $10 \mathrm{~cm} / 8,5 \mathrm{~cm} / 5 \mathrm{~cm}$ after drainage of approximatively $50 \mathrm{~mL}$ of purulent content.
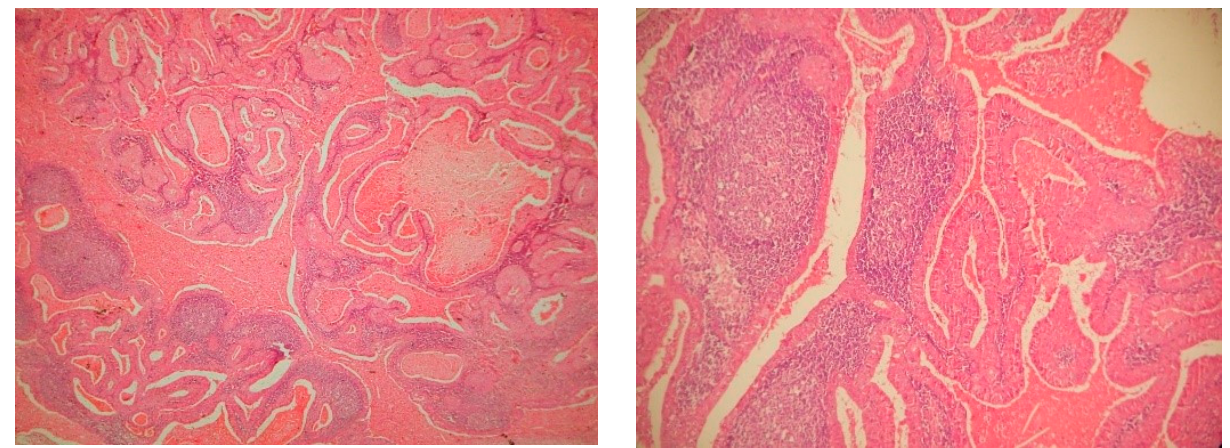

Figure 5. Microscopy, Hematoxylin- Eosin staining, $\times 10$, histopathological findings in Warthin's tumor: a lesion that had a mixed appearance, consisting of solid and cystic areas; the tumor was composed of two entities: the epithelial component and a lymphoid stroma, composed of mature lymphocytes, with some germinal centers.

Postoperative evolution was favorable, with good aesthetic results and no postoperative complications or tumor recurrence at the 10 month follow-up examination (Figure 6).

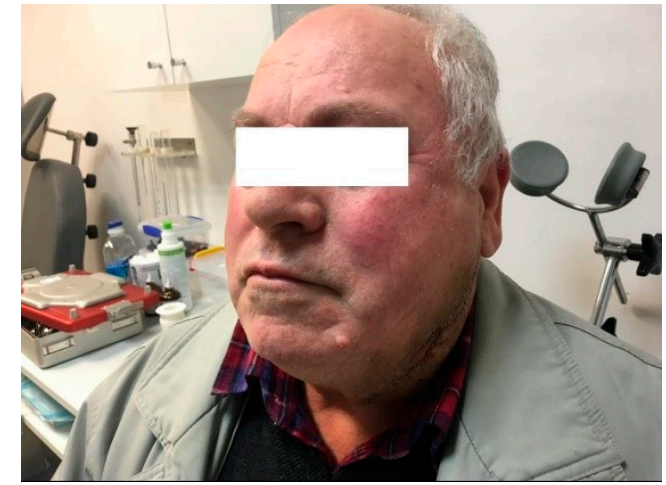

(a)

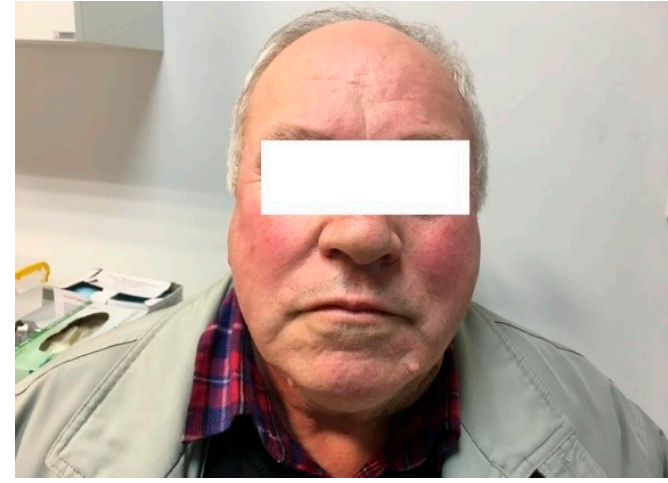

(b)

Figure 6. Postoperative results, four weeks after the surgery: (a) left lateral view; (b) anterior view. 


\section{Discussions}

Warthin's tumor represents the second most frequent benign salivary gland neoplasm, with incidence varying between 3.5 and $30 \%$, according to reports from various countries [5]. Being more frequent in males aged 40 to 70 years, WT is correlated with smoking and alcohol consumption [5]. The total incidence of WT has increased over the past decades, Franzen et al. [6] reporting a rise of cases from 20.6\% between 1975 and 1986, to 44.9\% between 2008 and 2017. This study also found WT to be the most common histological parotid gland tumor between 1997 and 2017, while also observing a decrease of patients' age from 68 to 62 years. Kadletz et al. [7] evaluated 919 patients treated for benign parotid gland tumors and reported a rising incidence WT, from 9.1\% in the early 1960 s, to $50 \%$ in 2000 s and $60.6 \%$ in 2015 . This study [7] suggests the occurrence of a shift in the prevalence of benign parotid gland tumors, Warthin's tumor becoming the most common. The same study [7] reported a significantly higher BMI of patients with WT in comparison with other parotid gland neoplasms. Furthermore, a link was observed between being overweight/obese and tumor size. Psychogios et al. [8] reported an association of smoking with the presence of WT in 93\% of patients, compared with only $47 \%$ of patients diagnosed with pleomorphic adenoma. However, due to the increasing number of women smoking, the sex ratio has shown a tendency of equalization during the last few decades [5,9]. In a review article on the matter [5], the incidence of WT in smokers was found to be eight times higher than in non-smokers, also radiation exposure and autoimmune diseases were incriminated in the etiology. Even though these studies $[7,8]$ were conducted on patients from single institutions, the findings are very intriguing and multicenter epidemiological studies would be of great significance.

Also known as cystic adenolymphoma, WT consists of two histological components. The epithelial component of bi-layered oncocytic and basaloid epithelium-forming cystic structures, glands and papillae, and a stroma component containing lymphoid tissue resembling lymph nodes [10]. The pathogenesis of cystic adenolymphoma is subject to long-standing debate, two theories being favored by the majority of authors [5,10-12]. The more recent explanation is that WT, as a benign epithelial neoplasm, entraps a lymphoid reaction inside the tumor stroma. The association between epithelial metaplasia and lymphocytes found in WT, advocates an antigen-induced response of lymphocytes. This theory would partially explain the association between WT and autoimmune diseases. However, the most preferred theory states that WT arises from heterotopic salivary ductal cells trapped within the parotid lymph nodes and the metaplasia would be induced by carcinogens $[5,10,12]$. Recent immunohistochemical and genetic studies suggest GAPDH as a potential gene involved in the pathogenesis of Warthin's tumor, but further research is needed for confirmation and understanding of its clinical implications [11].

The rising incidence of WT could also be explained by the accidental discovery on imaging studies and widespread use of ultrasonography (US), certain centers having US included in the basic ENT training [8]. As a result of the slow growth rate and high incidence of incidental diagnosis, deforming bulky WT are rare, tumor size varying from a few millimeters to a few centimeters, with an average of 2 to $4 \mathrm{~cm}$ in diameter [5]. Our research into the literature found only one case presentation similar to the one we are presenting, Salaria et al. [13], describing a massive disfiguring Warthin tumor measuring up to $20 \mathrm{~cm}$, being the largest Warthin's tumor described.

Regarding best imaging methods for WT diagnosis, magnetic resonance imaging (MRI) is certainly the most accurate, providing a more detailed description on the extension of the mass, finer intimate reports with important structures of the neck [14], especially with the more advanced techniques of diffusion-weighted MRI [5]. Nevertheless, this investigation is time consuming and expensive, hence computed tomography (CT) is a more accessible method. Zhang et al. [14] described the use of CT textural image biomarkers (IBM), as possible means of preoperative differential diagnostics between pleomorphic adenoma and Warthin's tumor. In our case, contrast enhanced CT scan was used due to its increased availability in our department and the experience of our radiologists with this type of investigation. The association between CT scan and fine needle aspiration biopsy (FNAB) is thought 
to grant accurate diagnosis [5,10]. In addition, ultrasound is of great importance for guiding the FNAB, allowing the radiologist to evaluate other parotid gland abnormalities and facilitate sampling of the solid tumor component $[5,15]$. A review of the literature evaluating parotid FNAB, carried out by Liu et al. [16], concluded that this investigation has high specificity $(98 \%)$, moderate sensitivity $(78 \%)$ and excellent global accuracy $(96 \%)$ in differentiating between benign and malignant lesions. These results are supported by a review on cytopathology and diagnostics of WT [5], reporting a low rate of false positive results $(<3.3 \%)$. Even though reporting a positive predictive value (PPV) over $96 \%$ for FNAB, some authors $[13,17]$ advocate that the prevalence of multifocal lesions and imperfect specificity and sensitivity are arguments against its use. Another argument opposing FNAB in our case is the fact that atypical cases are more difficult to diagnose cytologically [13]. An alternative to FNAB was open biopsy, however it has been largely abandoned due to the risk of tumor spillage, nerve damage and salivary fistula formation [16]. The third option for histologic diagnosis is core-biopsy, but because of the significant size of the needle, there have been reports of tumor seeding along the tract [16], leaving FNAB as the most desirable option.

The risk of malignant degeneration is extremely rare [18], however multifocality and bi-laterality are frequent, especially in heavy smokers. Contrary to pleomorphic adenoma, in WT surgical margins are not as important due to the very low incidence or recurrence [4]. As result of the low risk of recurrence and malignant transformation, there is a scholarly debate regarding the optimal surgical procedure. A review of the literature on this subject, realized by Quer et al. [4], proposed surgical guidelines for each category of benign parotid gland tumors. Their recommendations regarding surgical approach are based on size and location of the benign parotid gland tumor, hence classifying them in four categories. Tumors classified as I and II are less than $3 \mathrm{~cm}$ in size, located superficially and respectively deep in the parotid gland. The last two categories include tumors larger than $3 \mathrm{~cm}$, with category III involving two levels of the gland and category IV involving more than two levels. Quer et al. [4] consider extracapsular excision a good option for Warthin's tumors category I and II if the surgeon has experience and they also recommend using a facial nerve monitor. However, they consider that category I and II tumors are also amenable for partial parotidectomy. For tumors larger than $3 \mathrm{~cm}$ (categories III and IV), the authors [4] propose conventional parotidectomy, with the extent related to the extent of the tumor as a general rule. Moreover, category III WT can also benefit from extracapsular dissection in the hand of the experienced surgeon, with a high volume of parotid gland surgeries, providing a facial nerve monitor is used.

Most authors advocate surgical excision for WT, yet conservative treatment could be an option for older patients with associated comorbidities $[9,15,17]$. Arguments favouring conservative treatment include low malignant transformation and recurrence rates. Additionally, it is considered that, in some cases, tumour recurrences are mistaken with synchronous/metachronous neoplasia, due to the common multifocal nature of Warthin's tumor [5,15,17].

The surgical approach chosen by the senior author in this case was tumor excision with superficial parotidectomy, complying with the current literature recommendations, while managing to preserve all facial nerve functions. Esthetic results are also important, complete parotidectomy leaving a large defect in the parotid region, requiring muscle flaps. Another argument favoring superficial parotidectomy is a lower chance of developing Frey's syndrome.

\section{Conclusions}

We exemplify a rare encounter of a giant parotid gland tumor successfully treated with partial parotidectomy. We consider the lack of surgical complications to be attributed to the superficial location of the tumor. We grant the location of Warthin's tumor and surgeon's experience to be of great value in deciding on the treatment management. 
Author Contributions: Conceptualization, I.M.P. and S.A.; methodology I.M.P. and N.P.; software, non-applicable; validation, I.M.P., A.A. and S.A.; formal analysis, non-applicable; investigation, I.M.P. and N.P.; resources, S.A.; data curation, I.M.P. and N.P.; writing-original draft preparation, I.M.P., N.P. and A.A.; writing-review and editing, A.A. and S.A.; visualization, I.M.P. and S.A.; supervision, A.A. and S.A.; project administration, S.A.; funding acquisition, non-applicable. All authors have read and agreed to the published version of the manuscript.

Funding: This research received no external funding.

Conflicts of Interest: The authors do not report any conflict of interest.

\section{References}

1. Liu, X.; Du, D.; Lin, X. Large and multiple Warthin's tumors of bilateral parotid glands: A case report of bilateral regional excision of the parotid. Oral Maxillofac. Surg. Cases 2018, 4, 118-123. [CrossRef]

2. So, T.; Sahovaler, A.; Nichols, A.; Fung, K.; Yoo, J.; Weir, M.M.; MacNeil, S.D. Utility of clinical features with fine needle aspiration biopsy for diagnosis of Warthin tumor. J. Otolaryngol. Head Neck Surg. 2019, 48, 41. [CrossRef] [PubMed]

3. Vogl, T.J.; Albrecht, M.H.; Nour-Eldin, N.-E.-D.A.; Ackermann, H.; Maataoui, A.; Stöver, T.; Bickford, M.W.; Stark-Paulsen, T. Assessment of salivary gland tumors using MRI and CT: Impact of experience on diagnostic accuracy. Radiol. Med. 2017, 123, 105-116. [CrossRef] [PubMed]

4. Quer, M.; Poorten, V.V.; Takes, R.P.; Silver, C.E.; Boedeker, C.C.; De Bree, R.; Rinaldo, A.; Sanabria, A.; Shaha, A.R.; Pujol, A.; et al. Surgical options in benign parotid tumors: A proposal for classification. Eur. Arch. Oto Rhino Laryngol. 2017, 274, 3825-3836. [CrossRef] [PubMed]

5. Sučić, M.; Ljubić, N.; Perković, L.; Ivanović, D.; Pažanin, L.; Radovanović, T.S.; Župnić-Krmek, D.; Knežević, F. Cytopathology and diagnostics of Warthin's tumour. Cytopathology 2020, 31, 193-207. [CrossRef] [PubMed]

6. Franzen, A.M.; Kaup Franzen, C.; Guenzel, T.; Lieder, A. Increased incidence of Warthin tumours of the parotid gland: A 42-year evaluation. Eur. Arch. Oto Rhino Laryngol. 2018, 275, 2593-2598. [CrossRef] [PubMed]

7. Kadletz, L.; Grasl, S.; Perisanidis, C.; Grasl, M.C.; Erovic, B.M. Rising incidences of Warthin's tumors may be linked to obesity: A single-institutional experience. Eur. Arch. Oto Rhino Laryngol. 2019, 276, 1191-1196. [CrossRef] [PubMed]

8. Psychogios, G.; Vlastos, I.; Thölken, R.; Zenk, J. Warthin's tumour seems to be the most common benign neoplasm of the parotid gland in Germany. Eur. Arch. Oto Rhino Laryngol. 2020, 277, 2081-2084. [CrossRef] [PubMed]

9. Jechova, A.; Kuchar, M.; Novak, S.; Koucky, V.; Dostalova, L.; Zabrodsky, M.; Kalfert, D.; Plzak, J. The role of fine-needle aspiration biopsy (FNAB) in Warthin tumour diagnosis and management. Eur. Arch. Oto Rhino Laryngol. 2019, 276, 2941-2946. [CrossRef] [PubMed]

10. Orabona, G.D.; Abbate, V.; Piombino, P.; Romano, A.; Schonauer, F.; Iaconetta, G.; Salzano, G.; Farina, F.; Califano, L. Warthin's tumour: Aetiopathogenesis dilemma, ten years of our experience. J. Cranio Maxillofac. Surg. 2015, 43, 427-431. [CrossRef] [PubMed]

11. Mandic, R.; Agaimy, A.; Pinto-Quintero, D.; Roth, K.; Teymoortash, A.; Schwarzbach, H.; Stöhr, C.G.; Rodepeter, F.R.; Stuck, B.A.; Bette, M. Aberrant Expression of Glyceraldehyde-3-Phosphate Dehydrogenase (GAPDH) in Warthin Tumors. Cancers 2020, 12, 1112. [CrossRef] [PubMed]

12. Rehani, S. Warthin's Tumour: A Case Report and Review on Pathogenesis and its Histological Subtypes. J. Clin. Diagn. Res. 2014, 8, ZD37-ZD40. [CrossRef] [PubMed]

13. Salaria, N.; Garg, U.; Kumar, S.; Verma, D.; Sharma, N.; Singh, K. Giant Warthin's Tumour of the Parotid Gland: A Rare Case Report. Indian J. Otolaryngol. Head Neck Surg. 2019, 71, 839-843. [CrossRef] [PubMed]

14. Zhang, D.; Li, X.; Lv, L.; Yu, J.; Yang, C.; Xiong, H.; Liao, R.; Zhou, B.; Huang, X.; Liu, X.; et al. Improving the diagnosis of common parotid tumors via the combination of $\mathrm{CT}$ image biomarkers and clinical parameters. BMC Med. Imaging 2020, 20, 38. [CrossRef] [PubMed]

15. Vlantis, A.C.; Ng, S.K.; Mak, C.K.; Cheung, J.M.; Chan, A.B.; Van Hasselt, C.A. If cytology of Warthin tumor is accurate, can management be conservative? Ear Nose Throat J. 2016, 95, 185-188. [PubMed]

16. Liu, C.C.; Jethwa, A.R.; Khariwala, S.S.; Johnson, J.; Shin, J.J. Sensitivity, Specificity, and Posttest Probability of Parotid Fine-Needle Aspiration: A Systematic Review and Meta-analysis. Otolaryngol. Neck Surg. 2015, 154, 9-23. [CrossRef] [PubMed] 
17. Schwalje, A.; Uzelac, A.; Ryan, W. Growth rate characteristics of Warthin's tumours of the parotid gland. Int. J. Oral Maxillofac. Surg. 2015, 44, 1474-1479. [CrossRef] [PubMed]

18. Alnoor, F.N.U.; Gandhi, J.S.; Stein, M.K.; Solares, J.; Gradowski, J.F. Prevalence of Lymphoid Neoplasia in a Retrospective Analysis of Warthin Tumor: A Single Institution Experience. Head Neck Pathol. 2020, 1-7. [CrossRef] [PubMed]

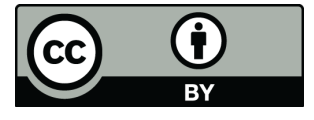

(C) 2020 by the authors. Licensee MDPI, Basel, Switzerland. This article is an open access article distributed under the terms and conditions of the Creative Commons Attribution (CC BY) license (http://creativecommons.org/licenses/by/4.0/). 